\title{
Changes in caesarean section rates and milk feeding patterns of infants between 1986 and 2013 in the Dominican Republic
}

\author{
John D McLennan* \\ Departments of Pediatrics, Psychiatry, and Community Health Sciences, Cumming School of Medicine, University \\ of Calgary, TRW Building, 3rd Floor, 3280 Hospital Drive NW, Calgary, Alberta, Canada, T2N 4Z6
}

Submitted 24 October 2015: Final revision received 16 March 2016: Accepted 18 March 2016: First published online 18 April 2016

\begin{abstract}
Objective: The relationship between caesarean sections (C-sections) and infant feeding varies between different samples and indicators of feeding. The current study aimed to determine the relationship between C-sections and five indicators of infant milk feeding (breast-feeding within $1 \mathrm{~h}$ after delivery, at the time of the survey (current) and ever; milk-based prelacteal feeds; and current non-breast milk use) over time in a country with a rapidly rising C-section rate.

Design: Secondary data analysis on cross-sectional data from Demographic and Health Surveys from six different time points between 1986 and 2013.

Setting: Dominican Republic.

Subjects: Infants under 6 months of age.

Results: Over $90 \%$ of infants were ever breast-fed in each survey sample. However, non-breast milk use has expanded over time with a concomitant drop in predominant breast-feeding. C-section prevalence has increased over time reaching $63 \%$ of sampled infants in the most recent survey. C-sections remained significantly related to three infant feeding practices - the child not put to the breast within $1 \mathrm{~h}$ after delivery, milk-based prelacteal feeds and current non-breast milk use - in multivariate models that included sociodemographic control variables. However, current non-breast milk use was no longer related to C-sections when milk-based prelacteal feeds were factored into the model.

Conclusions: Reducing or avoiding milk-based prelacteal feeds, particularly among those having C-sections, may improve subsequent breast-feeding patterns. Simultaneously, efforts are needed to understand and help reduce the exceptionally high C-section rate in the Dominican Republic.
\end{abstract}

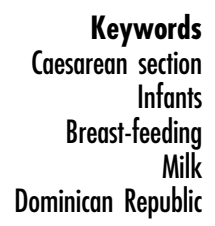

Caesarean section (C-section) rates have been increasing in many countries worldwide, although the increase may vary by wealth strata within countries, with the lower wealth strata in some low-income countries having inadequate access $^{(1)}$. A minimum C-section rate in a population is one indicator of adequate maternal health care, although there is no consensus as to what that minimum level should be. Rates less than $5 \%$ have been found to relate to maternal and perinatal deaths potentially secondary to the failure to perform necessary C-sections ${ }^{(2)}$. The WHO has stated that 'rates higher than $10 \%$ (at a population level) are not associated with reductions in maternal and newborn mortality rates' (p.1) ${ }^{(3)}$. Of particular concern from a child nutrition perspective is the potential interference C-sections may have on the initiation of breast-feeding and subsequent exclusive use of breast milk in the early months of an infant's life. However, this adverse relationship is not found consistently across studies, particularly when other variables have been factored in ${ }^{(4,5)}$. Some of this variation may be a function of different settings and the use of different infant feeding indicators (e.g. 'any' $v$. 'exclusive breast-feeding'). Further examination of this complex relationship is critical given rising $\mathrm{C}$-section rates in some settings and the potential that this surgical procedure may undermine breast-feeding.

For infants born by C-section, a number of factors have been identified that decrease initiation or exclusivity of breast-feeding, including separation of mother and infant post-delivery, post-surgical pain and hormonal differences (e.g. maternal prolactin and oxytocin) between a C-section and vaginal delivery ${ }^{(6,7)}$. However, some linkages between C-sections and infant feeding may be mediated by third variables. For example, in some countries greater wealth is related to both a higher likelihood of having a C-section and a lower likelihood of breast-feeding ${ }^{(8)}$. In addition, the nature and strength of the relationship between C-sections and infant feeding may vary across 
different infant feeding indicators. Indicators in different studies have included: any breast-feeding, breast-feeding within $1 \mathrm{~h}$ after delivery, use of prelacteal feeds (i.e. any food or liquid before the first breast-feed ${ }^{(9)}$ or before breast-feeding is established; often operationalized as the first $3 \mathrm{~d}$ postpartum), duration of breast-feeding and exclusivity of breast-feeding at various ages.

Early and exclusive breast-feeding may be most at risk following a C-section. Studies have found that C-sections are related to a lower likelihood of breast-feeding within $1 \mathrm{~h}$ and an increased likelihood of prelacteal feeding ${ }^{(8,10)}$. However, it has been proposed that this is not inevitable if adequate or extra supports are provided post-delivery to establish breast-feeding after a C-section ${ }^{(6)}$. This proposition is supported by a finding from a non-experimental study in a hospital setting in India in which no differences in rates of breast-feeding at $1 \mathrm{~h}$ post-delivery were found between those having a C-section $v$. vaginal delivery when lactation support was provided to all mothers ${ }^{(11)}$.

A weaker relationship may be found for indicators of breast-feeding that are more distal from the C-section event such as duration or exclusivity at later follow-up points (i.e. beyond the immediate postpartum period). For example, Perez-Escamilla and colleagues in Mexico found that among women who initiated breast-feeding and continued for at least 1 month, having had a C-section was not related to duration of breast-feeding while controlling for other variables (e.g. maternal education) ${ }^{(5)}$. Similarly, within a meta-analytic study, having had a C-section was not related to whether infants were fully or exclusively breast-fed at 6 months among those mothers who had initiated breast-feeding ${ }^{(4)}$. However, an adverse relationship may be found if C-sections interrupt breast-feeding initiation, such as breast-feeding within $1 \mathrm{~h}$, which itself is a predictor of subsequent breast-feeding regardless of delivery type. For example, breast-feeding within $1 \mathrm{~h}$ postpartum has been found to relate to: (i) lower likelihood of introducing prelacteal feeds; (ii) subsequent breast-feeding; and (iii) exclusive breast-feeding at followup $^{(10,12-14)}$. As well, avoiding prelacteal feeds is related to greater likelihood of subsequent breast-feeding ${ }^{(13)}$.

Taking advantage of consistent data collection occurring in the same country over time may allow for identification of trends that are obscured when data are lumped across countries or lost if the focus is only on recent cross-sectional data. It is proposed that examining C-section rates and infant feeding patterns over time in the Dominican Republic (DR) may be informative. The DR has been a regular participant in national surveys over time, in particular the Demographic and Health Surveys (DHS), which have included measures of C-sections and infant feeding. The DR also has one of the highest C-section rates in the world. In a 137-country study based on available data from 2008 (or most closely available data to that year), the DR tied for the second highest C-section rate with Iran at $41.9 \%$, with only Brazil having a higher C-section rate at $45.9 \%{ }^{(2)}$. Since then, the C-section rate in the DR has risen further, with a preliminary report from a 2014 DR Multiple Indicator Cluster Survey reporting a rate of $58.1 \%$ of those born in the last 2 years ${ }^{(15)}$. A rise in the C-section rate from 21 to $56 \%$ was estimated in a summary of findings from DHS rounds in the DR from 1991 to $2013^{(16)}$.

It was hypothesized that, within the DR: (i) those who had a C-section would be less likely to breast-feed and more likely to use non-breast milk and that this relationship would persist after controlling for confounding variables; and (ii) the receipt of a C-section would be more strongly related to immediate postpartum $v$. later infant feeding practices. Therefore, the aims of the present study were to determine: (i) the C-section rate and patterns of infant feeding in the DR over time; (ii) whether receipt of a C-section is related to infant feeding patterns and, if so, whether this relationship persists after controlling for potentially confounding variables; and (iii) whether the receipt of a C-section is related to more distal infant feeding indicators after feeding practices in the immediate postpartum period are considered.

\section{Methods}

\section{General}

The present study is based on secondary data analysis of data sets from the DHS. DHS studies obtain ethics approval within host countries.

\section{Sample}

The DHS uses a multi-staged sampling design (sample of households within a sample of enumeration areas) with the aim of obtaining a nationally representative sample ${ }^{(17,18)}$. Sample weights are included in the databases to take into consideration the sampling strategy. Within selected households, women between 15 and 49 years of age are invited to complete the women's interview which contains a series of questions on infant feeding practices for those who have had children within the previous 5 years ${ }^{(18)}$.

Samples for this specific study were drawn from data sets from all six DHS from the DR spanning 1986-2013. Extracted samples from each data set were composed of children who were: (i) living in selected households; (ii) under 6 months of age at the time of the survey; (iii) singleton births; and (iv) alive at the time of the survey. In addition, the samples were restricted to the participating mothers who responded to the C-section question and current breast-feeding question; and, if currently breast-feeding, responded to all the current infant dietary intake questions for the previous $24 \mathrm{~h}$ to allow for current breast-feeding status classification. Of the 3685 infants less than 6 months of age across the six surveys, $91.8 \%$ ( $n$ 3384) met the inclusion criteria. With weighting, the sample size is 3099. Sample sizes varied substantially between survey years. As the study limited the sample to children under 6 months of age, the summary values are 
not the same as those reported in the final DHS reports which are based on the full survey samples without this age restriction.

\section{Measures}

Dependent variables (infant milk feeding indicators)

Dependent variables were the following infant milk feeding behaviours.

1. Ever breast-fed: mother's response to a 'yes/no' question.

2. How soon after birth put to the breast: responses in the DHS data set were dichotomized to 'within 1 h' $v$. 'not within 1 h'.

3. Milk-based prelacteal feeds: a 'yes' response to any non-breast milk type (i.e. infant formula; powdered/tin; fresh liquid, e.g. cow's) used in the first $3 \mathrm{~d}$ of birth was coded as 'yes,' otherwise coded 'no'.

4. Current breast-feeding status: classification into the following categories was based on 'yes'/no' response to questions on whether currently breast-feeding (i.e. at the time of the survey interview) and response pattern to a series of questions about the child's liquid and food consumption in the $24 \mathrm{~h}$ period prior to the interview.

a. Exclusively breast-fed: is defined as nothing other than breast milk except for medicine, vitamins, minerals and oral rehydration solution. For the present study this was operationalized as a 'yes' response to current breastfeeding question AND a 'no' response to all questions about foods or liquids given in the previous $24 \mathrm{~h}$.

b. Predominantly breast-fed: allows for water and/or water-based drinks (excluding food-based liquids, e.g. infant formula) in combination with breast milk. This was operationalized in the present study as a 'yes' response to current breast-feeding question AND a 'yes' response to any of the liquid questions (except nonbreast milk) AND a 'no' response to non-breast milk and all semi-solid/solid food questions in the last $24 \mathrm{~h}$.

c. Partially breast-fed: is defined as breast milk in combination with any semi-solid/solid foods or foodbased liquids (i.e. beyond the beverages allowed under predominantly breast-fed). This was operationalized in the present study as a 'yes' response to current breastfeeding question AND a 'yes' response to any non-breast milk and/or semi-solid/solid food item(s).

d. Not breast-fed: operationalized in the present study as a 'no' response to current breast-feeding question.

Although the four categories are used to describe changes in breast-feeding across surveys, this indicator is dichotomized to exclusive $v$. non-exclusive breast-feeding for the examination of its relationships with C-sections.

5. Current non-breast milk use: this was based on a 'yes' response to any non-breast milk (i.e. infant formula; powdered/tinned; fresh liquid, e.g. cow's) use reported as consumed in the $24 \mathrm{~h}$ before the survey interview.

\section{Independent variable}

The independent variable was caesarean section (C-section): whether delivery was C-section or vaginal. No additional details were available as to whether C-sections were planned pre-labour, emergencies and/or repeat. Also not available in the data set was whether or not the vaginal deliveries included an operative component.

\section{Control variables}

Several characteristics that were available across all data sets and for which there is empirical evidence or theory that implicates their potential relationship to both infant feeding practices and C-sections were used as control variables in the multivariate models. These included the following.

1. Child birth order: this was dichotomized to first and later to control for primiparous $v$. multiparous effects.

2. Place of residence: this used a DHS dichotomized variable of urban/rural.

3. Maternal education: this used a continuous measure of reported years of education.

4. Maternal age: this used a continuous measured in years.

5. Mother's work status: this used a DHS dichotomized variable of 'yes/no' to capture whether the mother worked outside the home or not.

6. Number of prenatal care visits: respondent indicated the number of prenatal care visits attended.

7. Child age at time of the survey: this was measured in months and is used in the models considering current infant feeding practices (as opposed to those shortly after birth, where child age at the time of the survey should not have an effect).

Two additional variables, which were not available for the earliest data sets but were included given their importance in previous studies, are the following.

8. Wealth index: this was based on quintiles generated from a DHS-developed composite measure which includes household assets and facilities ${ }^{(19)}$. This measure was not available for the two earliest surveys.

9. Place of delivery: this question was introduced in 1991. As there were few home births and 'others', this variable was dichotomized to birth at public $v$. private institutions.

Finally, the following variable was included in the models to control for effects from merging survey samples from different time periods.

10. Phase ('year') of survey: this ranged from 1 (1986) to 6 (2013). This was dummy coded and not assumed to be a simple continuous measure.

\section{Analysis}

First, descriptive analyses were used to describe changes in infant feeding practices and C-sections over time in the DR. Second, $\chi^{2}$ analyses were used to examine the relationship between $\mathrm{C}$-sections and each of the infant feeding indicators. Third, Pearson's $\chi^{2}$, linear-by-linear 
association and Student $t$ tests were used to examine the relationship between control variables and infant feeding indicators that had been identified as related to C-sections in the previous mentioned analysis. Fourth, logistic regression models were used to examine the relationship between C-sections and the infant feeding indicators that were related to C-sections in bivariate analysis while incorporating the control variables which had demonstrated a significant relationship to both C-section and an infant feeding indicator within bivariate analysis. Fifth, the final logistic regression model further examined the relationship between C-sections and infant feeding indicators, this time by including preceding infant feeding practice in the model (e.g. put to the breast within $1 \mathrm{~h}$ for subsequent non-breast milk use). Statistical significance was set at the more conservative $P<0.01$ given the power from the moderately large sample size and the number of statistical tests. The statistical software package IBM SPSS Statistics Version 20 was used for all analyses.

Weighting provided within each DHS data set, which takes into account sampling design, was used for the descriptive analysis to generate values that estimate population prevalence for each survey. Weighting was not used for bivariate and multivariate analyses as per DHS recommendations ${ }^{(20)}$.

\section{Results}

Although ever breast-fed levels among infant less than 6 months of age have remained high over the time period considered (all samples $>90 \%$ ), there has been a decline in rates of many breast-feeding practices over time (Table 1). There is not an obvious trend over time in the proportion of infants who were breast-fed within $1 \mathrm{~h}$ after birth; however, the substantial drop between the penultimate and ultimate DHS rounds is concerning. The percentage of those predominantly breast-feeding at the time of the survey ('currently') dropped from $23.9 \%$ in 1986 to $6.1 \%$ in 2013 , with a concomitant increase in partial breast-feeding over the same time period ( 44.8 to $57.7 \%$ ). Although not captured for the full time period, there is a trend towards an increase in the percentage of infants receiving milk-based prelacteal feeds noted across the three most recent surveys (Pearson's $r=0.998$, $P=0.041)$. There is a marked increase in the C-section rate over time, with close to two-thirds of the 2013 sample of infants considered in the present study delivered this way $(63 \cdot 4 \%)$.

Combining the samples across surveys resulted in a sample size of 3384 infants (unweighted), $34.0 \%$ of whom

Table 1 Infant milk feeding indicators by survey year and by caesarean section (C-section) statust: secondary data analysis on cross-sectional data from Demographic and Health Surveys, Dominican Republic, 1986-2013

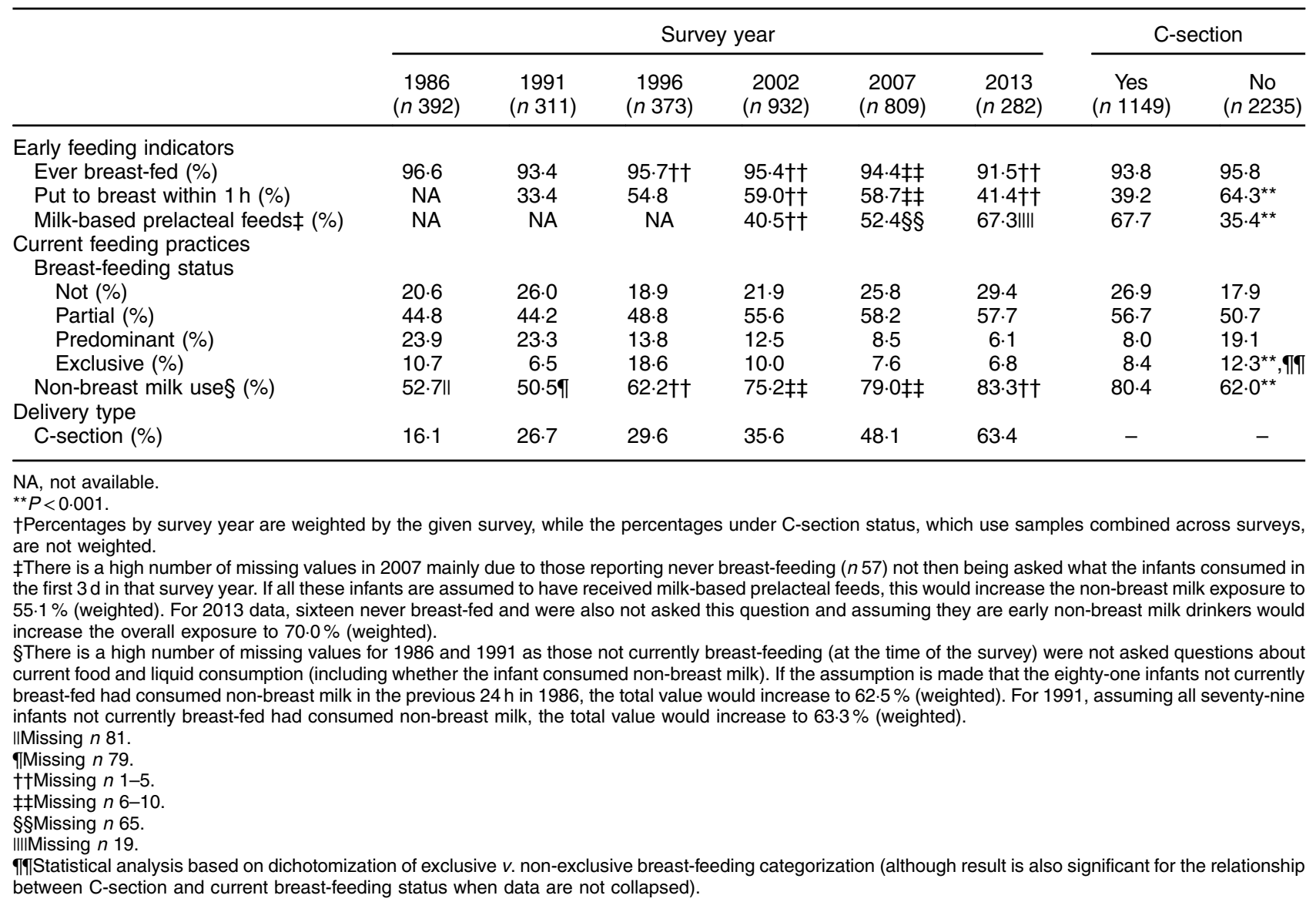


were delivered by C-section. There was no difference in the ever breast-fed rates between those children delivered by C-section $v$. vaginally. The vast majority of the infants delivered by C-section had ever been breast-fed and at a frequency only $2.0 \%$ less than those delivered vaginally (Table 1). In contrast, C-sections significantly decreased the likelihood of breast-feeding within $1 \mathrm{~h}$ and current exclusive breast-feeding, while increasing the likelihood of milk-based prelacteal feeds and current non-breast milk use.

All infant milk feeding indicators significantly related to $\mathrm{C}$-sections in the above analysis were then considered in relation to the control variables (Table 2). The following variables were consistently related to less preferred infant feeding practices for the four considered indicators, as well as with a higher likelihood of C-sections, in bivariate analysis: (i) mother being primiparous; (ii) higher maternal education; (iii) mother working outside the home; (iv) higher wealth status; (v) more antenatal visits; and (vi) delivery in a private facility. Urban residence was also associated with C-sections but less consistently related to less preferred infant feeding. Older child age was related to current less preferred infant feeding. Maternal age was unrelated to infant feeding practices.

These four infant feeding indicators were next examined within logistic regression models. First, two unadjusted models were calculated, one with all data available for a given infant feeding indicator and the other restricting the model to data from surveys 3 to 6 given that one of the key control variables, wealth index, was available only for the last four surveys (Table 3). After this sample restriction, C-sections remained significantly related to each of the four infant feeding indicators. After inclusion of control variables, having had a C-section was still related to the infant not having been put to the breast within the first hour, milk-based prelacteal feeds and current non-breast milk use, but not to current exclusive breast-feeding.

In the final set of models, the aim was to examine the impact of earlier infant feeding practices on subsequent feeding practices still related to C-sections in the above multivariate model (Table 4). First, putting the infant to the breast within $1 \mathrm{~h}$ was found to significantly reduce the odds of the infant receiving milk-based prelacteal feeds. Having the infant to the breast within $1 \mathrm{~h}$ was not a

Table 2 Relationship of control variables with infant feeding indicators and caesarean sections (C-sections) (unweighted): secondary data analysis on cross-sectional data from Demographic and Health Surveys, Dominican Republic, 1986-2013

\begin{tabular}{|c|c|c|c|c|c|c|c|c|c|c|c|c|c|c|c|}
\hline \multirow{3}{*}{$\begin{array}{l}\text { Control variables } \\
\text { Continuous }\end{array}$} & \multicolumn{3}{|c|}{$\begin{array}{l}\text { Put to breast within } \\
\qquad 1 \mathrm{~h}\end{array}$} & \multicolumn{3}{|c|}{$\begin{array}{l}\text { Milk-based prelacteal } \\
\text { feeds }\end{array}$} & \multicolumn{3}{|c|}{$\begin{array}{l}\text { Current exclusive } \\
\text { breast-feeding }\end{array}$} & \multicolumn{3}{|c|}{$\begin{array}{l}\text { Current non-breast } \\
\text { milk use }\end{array}$} & \multicolumn{3}{|c|}{ C-section } \\
\hline & \multicolumn{2}{|c|}{ Yes } & No & \multicolumn{2}{|c|}{ Yes } & No & \multicolumn{2}{|c|}{ Yes } & No & \multicolumn{2}{|c|}{ Yes } & No & \multicolumn{2}{|l|}{ Yes } & No \\
\hline & Mean & SD & Mean SD & Mean & $\mathrm{SD}$ & Mean SD & Mean & $\mathrm{SD}$ & Mean SD & Mean & SD & Mean SD & Mean & SD & Mean SD \\
\hline $\begin{array}{l}\text { Maternal education } \\
\text { (years) }\end{array}$ & $7 \cdot 3$ & $4 \cdot 4$ & $8.7^{\star *} 4.4$ & 9.6 & $4 \cdot 1$ & $6.9^{* *} 4.3$ & $6 \cdot 7$ & $4 \cdot 1$ & $7 \cdot 8^{* *} 4.5$ & $8 \cdot 4$ & 4.4 & $6 \cdot 0^{* *} 4 \cdot 2$ & $9 \cdot 7$ & $4 \cdot 2$ & $6 \cdot 6^{* \star} 4 \cdot 2$ \\
\hline $\begin{array}{l}\text { Maternal age } \\
\text { (years) }\end{array}$ & $24 \cdot 1$ & $5 \cdot 8$ & 24.4 & $24 \cdot 3$ & $5 \cdot 9$ & $24 \cdot 1$ & $23 \cdot 9$ & $5 \cdot 8$ & $24 \cdot 2$ & $24 \cdot 3$ & $5 \cdot 8$ & $24 \cdot 2$ & $24 \cdot 8$ & $5 \cdot 8$ & $23.9^{\star *} \quad 5.8$ \\
\hline $\begin{array}{l}\text { No. of antenatal } \\
\text { visits }\end{array}$ & $7 \cdot 2$ & 3.4 & $7 \cdot 9^{* *} 4.0$ & $8 \cdot 6$ & $3 \cdot 8$ & $7 \cdot 3^{\star *} 3 \cdot 2$ & $6 \cdot 9$ & $3 \cdot 3$ & $7 \cdot 6^{\star *} 3.7$ & $8 \cdot 0$ & 3.7 & $6.4^{* *} 3.3$ & 8.7 & $4 \cdot 0$ & $6.9^{* *} 3.3$ \\
\hline $\begin{array}{l}\text { Child age at time of } \\
\text { survey (months) } \dagger\end{array}$ & - & & - & - & & - & $1 \cdot 4$ & $1 \cdot 3$ & $2 \cdot 8^{* *} 1.4$ & $2 \cdot 8$ & 1.5 & $2 \cdot 1^{* *} 1.6$ & - & & - \\
\hline Categorical & $\%$ & & $\%$ & $\%$ & & $\%$ & $\%$ & & $\%$ & $\%$ & & $\%$ & $\%$ & & $\%$ \\
\hline \multicolumn{16}{|l|}{ Child birth order } \\
\hline Primiparous & $28 \cdot 6$ & & $40 \cdot 2$ & $41 \cdot \mathrm{C}$ & & $27 \cdot 5$ & $27 \cdot c$ & & $34 \cdot 0$ & $35 \cdot \varepsilon$ & & $26 \cdot 0$ & $39 \cdot 2$ & & $30 \cdot 2$ \\
\hline Multiparous & 71.4 & & $59 \cdot 8^{\star \star}$ & $59 \cdot($ & & $72 \cdot 5^{\star \star}$ & $73 \cdot c$ & & $66 \cdot 0^{*}$ & $64 \cdot 2$ & & $74 \cdot 0^{\star *}$ & $60 \cdot 8$ & & $69 \cdot 8^{\star *}$ \\
\hline \multicolumn{16}{|l|}{ Mother's work status } \\
\hline Outside home & $17 \cdot 3$ & & $25 \cdot 6$ & $26 \cdot$ & & $13 \cdot 3$ & $13 \cdot 6$ & & $20 \cdot 8$ & $22 \cdot 2$ & & $13 \cdot 7$ & $26 \cdot 1$ & & $16 \cdot 9$ \\
\hline Not outside home & $82 \cdot 7$ & & $74 \cdot 4^{\star \star}$ & 73.5 & & $86 \cdot 7^{\star \star}$ & $86 \cdot 4$ & & $79 \cdot 2^{\star *}$ & $77 \cdot \varepsilon$ & & $86 \cdot 3^{\star \star}$ & $73 \cdot 9$ & & $83 \cdot 1^{* *}$ \\
\hline \multicolumn{16}{|l|}{ Wealth index } \\
\hline Poorest & $40 \cdot 4$ & & $27 \cdot 2$ & $25 \cdot 3$ & & $45 \cdot 2$ & $45 \cdot 6$ & & 33.5 & 29.4 & & 49.9 & $22 \cdot 6$ & & $42 \cdot 7$ \\
\hline Poor & 24.6 & & $22 \cdot 1$ & 23. & & $24 \cdot 6$ & $22 \cdot \varepsilon$ & & $23 \cdot 7$ & $24 .($ & & $22 \cdot 4$ & $20 \cdot 9$ & & $25 \cdot 4$ \\
\hline Middle & $17 \cdot 4$ & & $19 \cdot 8$ & $20 \cdot$ & & $15 \cdot 7$ & $16 \cdot 3$ & & 18.5 & $20 \cdot 3$ & & $13 \cdot 2$ & $21 \cdot 7$ & & $16 \cdot 1$ \\
\hline Rich & 11.3 & & $18 \cdot 2$ & $18 . \varsigma$ & & 9.5 & 9.5 & & 14.8 & 16. & & $9 \cdot 2$ & 19.5 & & $10 \cdot 8$ \\
\hline Richest & $6 \cdot 3$ & & $12 \cdot 8^{\star \star}$ & $12 \cdot 6$ & & $5 \cdot 1^{\star *}$ & $5 \cdot \varepsilon$ & & $9 \cdot 5^{\star \star}$ & $10 \cdot 3$ & & $5 \cdot 4^{\star \star}$ & $15 \cdot 3$ & & $5 \cdot 0^{\star *}$ \\
\hline \multicolumn{16}{|l|}{ Place of residence } \\
\hline Urban & $54 \cdot 8$ & & 59.4 & $61 \cdot 7$ & & $52 \cdot 9$ & $48 \cdot 1$ & & 57.5 & $60 \cdot($ & & 46.5 & $63 \cdot 8$ & & $52 \cdot 8$ \\
\hline Rural & $45 \cdot 2$ & & $40 \cdot 6$ & 38.3 & & $47 \cdot 1^{\star \star}$ & $51 . \varsigma$ & & $42 \cdot 5^{\star \star}$ & $40 \cdot c$ & & $53 \cdot 5^{\star \star}$ & $36 \cdot 2$ & & $47 \cdot 2^{\star \star}$ \\
\hline \multicolumn{16}{|l|}{ Place of delivery $¥$} \\
\hline Public & $86 \cdot 5$ & & 67.5 & 69.5 & & 91.4 & 90.5 & & $76 \cdot 4$ & 74.5 & & $89 \cdot 1$ & $60 \cdot 8$ & & 88.5 \\
\hline Private & $13 \cdot 5$ & & $32 \cdot 5^{\star \star}$ & $30 \cdot 5$ & & $8 \cdot 6^{\star \star}$ & 9.5 & & $23 \cdot 6^{\star \star}$ & $25 \cdot 5$ & & $10 \cdot 9^{\star \star}$ & $39 \cdot 2$ & & $11.5^{\star \star}$ \\
\hline
\end{tabular}

${ }^{*} P<0.01 ;{ }^{* *} P<0.001$.

†Child age at time of survey assessed only for current feeding practices as it should not be relevant to events around the birth.

$\ddagger$ The small percentage with home delivery $(3.1 \%)$ and 'other' $(0.6 \%)$ were dropped for analysis by place of delivery. 


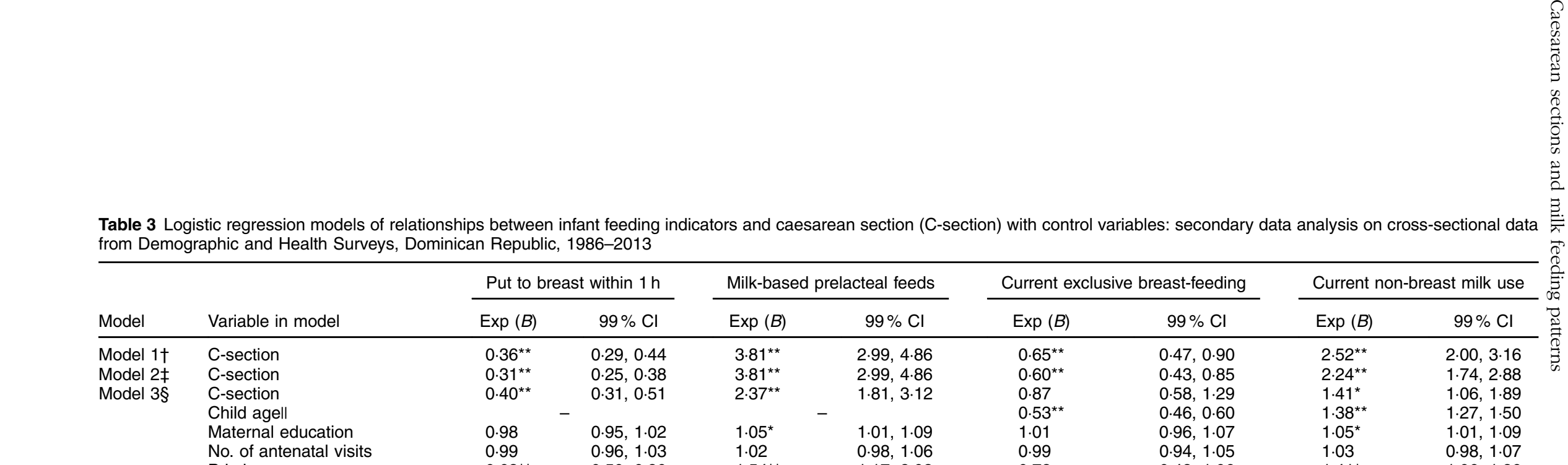

from Demographic and Health Surveys, Dominican Republic, 1986-2013

\begin{tabular}{|c|c|c|c|c|c|c|c|c|}
\hline Maternal education & 0.98 & $0.95,1.02$ & $1.05^{\star}$ & $1.01,1.09$ & 1.01 & $0.96,1.07$ & $1.05^{*}$ & $1.01,1.09$ \\
\hline No. of antenatal visits & 0.99 & $0.96,1.03$ & 1.02 & $0.98,1.06$ & 0.99 & $0.94,1.05$ & 1.03 & $0.98,1.07$ \\
\hline Primiparous & $0.63^{\star *}$ & $0.50,0.80$ & $1.54^{\star *}$ & $1.17,2.02$ & 0.72 & $0.48,1.06$ & $1.41^{*}$ & $1.06,1.86$ \\
\hline Mother working outside home & 0.80 & $0.60,1.07$ & $1.72^{\star \star}$ & $1.22,2.42$ & 0.73 & $0.44,1.22$ & $1.45^{*}$ & $1 \cdot 01,2 \cdot 10$ \\
\hline Wealth & \multicolumn{2}{|c|}{ Reference } & \multicolumn{2}{|c|}{ Reference } & \multicolumn{2}{|c|}{ Reference } & \multicolumn{2}{|c|}{ Reference } \\
\hline Poorest & 0.89 & $0.65,1.22$ & 1.37 & $0.97,1.95$ & 0.76 & $0.47,1.22$ & $1.44^{*}$ & $1.03,2.03$ \\
\hline Poor & 0.88 & $0.62,1.26$ & 1.31 & $0.88,1.97$ & 0.72 & $0.42,1.24$ & $1.77^{\star *}$ & $1.18,2.66$ \\
\hline Middle & 0.71 & $0.47,1.08$ & $1 \cdot 70^{*}$ & $1.06,2.72$ & 0.71 & $0.36,1.40$ & 1.53 & $0.94,2.48$ \\
\hline Rich & 0.78 & $0.46,1.30$ & 1.35 & $0.73,2.50$ & 0.80 & $0.33,1.94$ & 1.25 & $0.67,2 \cdot 34$ \\
\hline Richest & 1.21 & $0.94,1.55$ & 0.83 & $0.63,1.11$ & 0.94 & $0.64,1.37$ & 1.06 & $0.80,1.40$ \\
\hline Urban ( $v$. rural) & $0.56^{\star \star}$ & $0.41,0.77$ & $2 \cdot 32^{\star *}$ & $1.55,3.46$ & $0.36^{\star *}$ & $0.19,0.69$ & $1.92^{\star *}$ & $1.25,2.96$ \\
\hline Private delivery & & & & & & & & \\
\hline \multicolumn{9}{|l|}{ Survey phase } \\
\hline 3 & \multicolumn{2}{|c|}{ Reference } & & \multicolumn{2}{|c|}{ Reference } & \multicolumn{2}{|c|}{ Reference } \\
\hline 4 & 1.15 & $0.82,1.63$ & \multicolumn{2}{|c|}{ Reference } & $0.48^{\star *}$ & $0.30,0.78$ & $1.52^{\star}$ & $1 \cdot 13,2 \cdot 34$ \\
\hline 5 & 1.04 & $0.73,1.48$ & $1.74^{* *}$ & $1.32,2 \cdot 30$ & $0.49^{* *}$ & $0.29,0.81$ & $1.89^{* *}$ & $1.28,2.78$ \\
\hline 6 & 1.00 & $0.64,1.56$ & $2 \cdot 26^{\star *}$ & $1.50,3.40$ & $0.33^{* *}$ & $0.15,0.69$ & $2 \cdot 19^{\star *}$ & $1.29,3.72$ \\
\hline
\end{tabular}

${ }^{\star} P<0.01,{ }^{* *} P<0.001$.

Model 1: unadjusted, all data with C-section and given infant feeding indicator.

¥Model 2: unadjusted, sample restricted to survey Phases 3-6 as wealth index, used as a control variable in the next model, was not available for Phase 1 and 2 surveys

§Model 3: adjusted.
IIChild age at the time of the survey was not included in the models for feeding indicator specific to shortly after birth as this variable should not be related to these practices. 
Table 4 Logistic regression models examining relationships between infant feeding indicators and caesarean section (C-section) when factoring in preceding infant feeding indicators: secondary data analysis on cross-sectional data from Demographic and Health Surveys, Dominican Republic, 1986-2013

\begin{tabular}{|c|c|c|c|c|c|}
\hline \multirow[b]{2}{*}{ Model } & \multirow[b]{2}{*}{ Variable in model } & \multicolumn{2}{|c|}{ Milk-based prelacteal feeds } & \multicolumn{2}{|c|}{ Current non-breast milk use } \\
\hline & & $\operatorname{Exp}(B)$ & $99 \% \mathrm{Cl}$ & $\operatorname{Exp}(B)$ & $99 \% \mathrm{Cl}$ \\
\hline \multirow[t]{2}{*}{ Model $1 \dagger$} & C-section & $2 \cdot 96^{\star \star}$ & $2 \cdot 30,3.82$ & $2 \cdot 25^{\star \star}$ & $1 \cdot 76,2 \cdot 87$ \\
\hline & Put to breast within $1 \mathrm{~h}$ & $0.32^{\star \star}$ & $0.25,0.42$ & 0.84 & $0.67,1.05$ \\
\hline \multirow[t]{3}{*}{ Model $2 \ddagger$} & C-section & \multicolumn{2}{|r|}{$0.20,0.4 c$} & $1.69^{\star \star}$ & $1 \cdot 24,2 \cdot 29$ \\
\hline & Put to breast with $1 \mathrm{~h}$ & & & 0.95 & $0.70,1.28$ \\
\hline & Milk-based prelacteal feeds & & & $2 \cdot 96^{\star \star}$ & $2 \cdot 18,4.00$ \\
\hline \multirow[t]{20}{*}{ Model $3 \S$} & C-section & $1.93^{\star \star}$ & $1.45,2.57$ & $1 \cdot 28$ & $0.92,1.80$ \\
\hline & Put to breast within $1 \mathrm{~h}$ & $0.35^{\star *}$ & $0.27,0.46$ & & \\
\hline & Milk-based prelacteal feeds & \multicolumn{2}{|c|}{-} & $2 \cdot 69^{\star \star}$ & $1.94,3.74$ \\
\hline & Child agell & \multicolumn{2}{|c|}{ - } & $1.40^{\star \star}$ & $1.27,1.54$ \\
\hline & Maternal education & $1.05^{\star}$ & $1.01,1.09$ & 1.04 & $1.00,1.09$ \\
\hline & No. of antenatal visits & 1.02 & $0.97,1.06$ & 1.01 & $0.97,1.06$ \\
\hline & Primiparous & $1.37^{*}$ & $1.04,1.82$ & 1.21 & $0.88,1.67$ \\
\hline & Mother working outside home & $1.67^{\star *}$ & $1.17,2.37$ & 1.45 & $0.94,2.23$ \\
\hline & \multirow{2}{*}{\multicolumn{3}{|c|}{ Wealth }} & & \\
\hline & Poorest & & & \multicolumn{2}{|c|}{ Reference } \\
\hline & Poor & 1.36 & $0.94,1.95$ & 1.40 & $0.95,2.07$ \\
\hline & Middle & $1 \cdot 30$ & $0.86,1.96$ & $1 \cdot 77^{\star}$ & $1.10,2.85$ \\
\hline & Rich & $1.64^{*}$ & $1.01,2.67$ & 1.34 & $0.77,2.33$ \\
\hline & Richest & $1 \cdot 34$ & $0.71,2.53$ & 1.14 & $0.54,2.41$ \\
\hline & Urban ( $v$. rural) & 0.86 & $0.64,1.15$ & $1 \cdot 14$ & $0.83,1.57$ \\
\hline & Private delivery & $2.08^{\star *}$ & $1.37,3.14$ & 1.60 & $0.94,2.73$ \\
\hline & \multicolumn{3}{|l|}{ Survey phase } & \multirow{2}{*}{\multicolumn{2}{|c|}{ Reference }} \\
\hline & 4 & & & & \\
\hline & 5 & $1.83^{\star *}$ & $1.38,2.44$ & 0.99 & $0.72,1.36$ \\
\hline & 6 & $2 \cdot 31^{\star *}$ & $1.52,3.52$ & 1.07 & $0.65,1.75$ \\
\hline
\end{tabular}

${ }^{*} P<0.01,{ }^{* \star} P<0.001$

†Model 1: impact of putting infant to the breast within $1 \mathrm{~h}$ on subsequent infant feeding practices in the model (i.e. milk-based prelacteal feeds and current non-breast milk use).

$¥$ Model 2: impact of putting infant to the breast within $1 \mathrm{~h}$ hour AND milk-based prelacteal feeds on current non-breast milk use.

§Model 3: inclusion of control variables in the models.

॥Child age at the time of the survey was not included in the models for milk-based prelacteal feeds as this should not be related to this practice.

significant predictor of current non-breast milk use, however, although milk-based prelacteal feeds was a strong predictor of current non-breast milk use. Having a C-section no longer predicted current non-breast milk use in a full model when control variables and milk-based prelacteal feeds were factored into the model.

\section{Discussion}

At least some breast-feeding remains very common for Dominican infants; however, predominant breast-feeding is dropping rapidly with the high and growing use of non-breast milk, including in the first few days of life. In the background of these infant feeding changes is a substantial expansion of C-sections over time. C-sections in the DR are most strongly related to infants receiving milk-based prelacteal feeds, which may set in motion feeding approaches that undermine subsequent exclusive breast-feeding. This is supported by the finding that milk-based prelacteal feeds were associated with subsequent non-breast milk use and hence non-exclusive breast-feeding at the time of the surveys. Beyond differences by delivery type, that only 6.8 and $6.1 \%$ of children were categorized as exclusive and predominant breast-feeders, respectively, in the most recent DHS indicates an ongoing public health nutrition concern ${ }^{(16)}$.

These findings overlap with those of the study conducted by Perez-Escamilla and colleagues mentioned in the introduction; however, unlike that investigation, the present study included all eligible infants rather than examining a subset at follow-up (i.e. only those for whom breast-feeding was established $)^{(5)}$. In addition, the present study restricted analysis to infants under 6 months of age to reduce recall bias in contrast to studies such the one by Perez-Escamilla and colleagues from Mexico that asked about infant feeding for children up to 5 years of age. Despite these variations, both studies found that C-sections appeared to have a more consistent impact on immediate postpartum feeding in contrast to later time points. In contrast, Perez-Escamilla and colleagues found that C-sections also predicted not breast-feeding at all, while it did not in the present study. This may be in part due to the high rates of ever breast-feeding in this Dominican sample (overall 95.1\%) even for those having had a C-section (93.8\%); whereas in the Mexican study, only $81 \%$ of the children had had any breast-feeding overall and only $73 \%$ among those who had a C-section ${ }^{(5)}$.

The current study also overlaps with the previously cited meta-analytic study that drew on studies from 
different countries and also found that $\mathrm{C}$-sections negatively impact early but not later breast-feeding practices ${ }^{(4)}$. However, the meta-analysis further examined potential differences between types of C-section, which was not possible in this DR study. More specifically it identified that pre-labour ('elective') C-sections lowered the odds of breast-feeding relative to vaginal deliveries but that in-labour ('emergency') C-sections did not ${ }^{(4)}$. Similarly, an Italian study found elective C-sections were related to formula-feeding at discharge, but emergency C-sections were not $^{(21)}$.

Unfortunately, the DHS data set did not have variables which would allow for sub-categorization of C-sections. Given the potential differential effect of C-section types, this will be an important variable to include in future studies where possible. However, identifying a brief but accurate self-report indicator to validly distinguish C-section types that could be used in large populationbased studies like the DHS appears challenging ${ }^{(22)}$. A study investigating this very measurement issue happened to include a sample of Dominican mothers who had had C-sections at the largest maternity hospital in the $\mathrm{DR}^{(22)}$. Of interest, $49.1 \%$ of mothers in that DR sample indicated that a decision to have a C-section was made in the prenatal period $^{(22)}$.

Given the current, very high, C-section rate in the DR, a substantial majority must be assumed to fall within an elective category. Whereas elective C-sections may reduce neonatal risk for breech presentations compared with vaginal deliveries, elective C-sections have been found to increase risk (e.g. maternal and neonatal intensive care unit admissions) for cephalic presentations ${ }^{(23)}$. A further concern is related to repeat C-sections. While not identifiable within these data sets, the exceptionally high C-section rate in the DR will inevitably lead to a large proportion of women who will be faced with potential repeat C-sections and the associated maternal and infant risks $^{(24)}$.

Placing the infant to the breast as soon as possible after delivery is one of the ten steps to successful breast-feeding within the WHO-UNICEF Baby Friendly Hospital Initiative ${ }^{(9)}$. This practice may be particularly at risk from C-sections. The 2007 DR value of $58.7 \%$ was very consistent with a $58 \%$ mean value for the Latin American region reported from a global study ${ }^{(25)}$. However, a lower value noted in the 2013 DHS for the DR and a preliminary report of only $38.1 \%$ from the 2014 Multiple Indicator Cluster Survey of the $\mathrm{DR}^{(15)}$ may signal a recent downward trend in this practice.

A more critical practice, however, may be the extent of milk-based prelacteal feeds. This practice is demonstrating a clearer upward trend over time in the DR and is associated with subsequent non-breast milk use in the first 6 months of life. While the DHS questions on this topic ask specifically about liquid use, other than breast milk, in the first $3 \mathrm{~d}$, it does not tie the questions to the state of established breast-feeding. Nevertheless, this measure is commonly considered an acceptable proxy indicator of prelacteal feeding. Prelacteal feeds have been found to adversely impact any and exclusive breast-feeding ${ }^{(26)}$. This linkage is also supported by findings from experimental work in that an intervention study that reduced prelacteal feeds compared with a control group also improved exclusive breast-feeding at follow-up ${ }^{(27)}$. Of additional concern is a recent Latin American and Caribbean study (that included the DR) that found that those at lower-economic levels may disproportionately experience the adverse relationship between C-sections and use of prelacteal feeds ${ }^{(8)}$. Of note, this latter study and the current study focused exclusively on milk-based prelacteal feeds $v$. a broader inclusion of prelacteal liquids that may include items such as teas.

Although beyond the scope of the present paper, the current high and rapidly rising C-section rate in the DR is a concern in and of itself, beyond its impact on infant feeding. The DR is one in a cluster of Latin American countries with some of the highest C-section rates in the world; Brazil, Mexico, Argentina and Cuba also had rates $>35 \%$ in the previously cited review using 2008 data $^{(2)}$. Some of these Latin American countries (not the DR) participated in a cluster randomized trial that required second opinion for non-emergency C-sections, which found a small, but significant, reduction in C-sections in the intervention hospitals ${ }^{(28)}$. Given the continued high C-section rates, further intervention efforts are required.

\section{Limitations}

There are several limitations to the present study. First, as noted earlier, is the inability to tease out different types of C-sections (i.e. elective $v$. emergency) which is relevant given their apparent differential effects on infant feeding. Given that the C-section rate in the DR is substantially above recommended or expected levels based on estimates of medical need, the majority of C-sections are likely elective. A second limitation is the incomplete inclusion of potential confounding variables that may relate to both C-sections and breast-feeding, such as gestational age at birth, prenatal breast-feeding intention ${ }^{(29)}$ and maternal obesity $^{(6)}$. Maternal obesity has been found to relate to the likelihood of having a C-section ${ }^{(30)}$ and not breastfeeding $^{(31)}$. In the most recent DHS round from the DR, $20.8 \%$ of women (15-49 years of age) were classified as obese $\left(\mathrm{BMI} \geq 30 \cdot 0 \mathrm{~kg} / \mathrm{m}^{2}\right)$ and an additional $29 \cdot 7 \%$ as overweight (i.e. $\left.\mathrm{BMI}=25 \cdot 0-29 \cdot 9 \mathrm{~kg} / \mathrm{m}^{2}\right)^{(16)}$. As maternal BMI is now included in the DHS, this variable will be available for evaluation in future studies. Other control variables may not have been optimal. For example, number of prenatal care visits may not be an adequate proxy to indicate quality of prenatal care. In addition, a high number of prenatal care visits may, in some cases, be related to obstetric complications, which has prompted some studies to classify such subgroups separately from those categorized as having 
received an 'adequate' number of visits ${ }^{(32)}$. Third, information on infant feeding indicators are retrospective and in the case of information on feeding shortly after birth, could have occurred several months prior to the survey and therefore be at increased risk of recall inaccuracies. Fourth, only milkbased prelacteal feeds were considered in the present study, while other studies have considered all prelacteal feeds (e.g. sugar water). Fifth, the study was not able to separate out infant formula from other non-breast milk use. Sixth, while the DHS uses similar sampling strategies and questionnaire structures over time, variations over time may influence the extent of comparability. For example, in order to determine current breast-feeding categorization, responses to $24 \mathrm{~h}$ dietary intake questions are used. Typically, the $24 \mathrm{~h}$ dietary questions are based on responses to yes/no questions for a series of standard food groups. However, in 2002, the question was changed and asked about frequency of consumption of foods in the last $24 \mathrm{~h}$ for the same food groups. While information obtained from the 2002 questionnaire can be collapsed into the yes/no format for comparability, it is possible that this may have contributed some response variation between survey years. Finally, the lack of variables on immediate postpartum support in the postnatal period does not allow exploration of the potential protective effect such support may provide for preferable infant feeding practices under C-section conditions. That $23.5 \%$ of mothers reported no professional attention within $2 \mathrm{~d}$ postpartum in the latest DHS round from the DR, despite almost all deliveries occurring in hospitals, is of concern ${ }^{(16)}$. An older investigation of hospital-based obstetric care in the DR identified a number of concerns that, if persistent, decrease the likelihood that adequate postpartum support would be routinely available ${ }^{(33)}$. An additional variable not captured in the data was the extent of mother-infant skin-to-skin contact soon after delivery which has been found to relate to early initiation ${ }^{(34)}$ and exclusivity $^{(35)}$ of breast-feeding, as well as being impeded by C-section delivery ${ }^{(36)}$.

Despite these limitations, the present study finds consistent evidence that $\mathrm{C}$-sections are related to important infant feeding indicators (e.g. milk-based prelacteal feeds) in the DR based on data from a 27 -year period. The use of multiple infant feeding indicators, as well as restricting the sample to young infants to reduce the recall period, increases the strength of the findings. As well, these patterns of infant feeding are seen across time which may indicate these relationships are robust.

In the DR and in other contexts, reducing or avoiding early non-breast milk feeds, particularly among those having C-sections, may improve subsequent preferable infant feeding practices. Simultaneously, however, efforts are needed to understand and help reduce the exceptionally high C-section rate in the DR. Additional investigations of perinatal care in the DR, similar to the recent large-scale survey in Brazil, might shed additional light on factors related to C-sections ${ }^{(37)}$.

\section{Acknowledgements}

Acknowledgments: The author thanks Dr Michael Boyle and Dr Kathy Georgiades from the Offord Centre for Child Studies, McMaster University, for their critical feedback on earlier drafts of this paper. Thanks also go to the anonymous reviewers for this journal for their critical feedback which served to strengthen the final paper. Finally, the author thanks the families that participated in the DHS and the DHS programme that has made these data available for this study. Financial support: This research received no specific grant from any funding agency in the public, commercial or not-for-profit sectors. Conflict of interest: None. Authorship: The author developed the concept, completed all analysis and wrote the manuscript. Ethics of buman subject participation: This study was based on secondary data analysis of publically available data sets.

\section{References}

1. Cavallaro FL, Cresswell JA, Franca GV et al. (2013) Trends in caesarean delivery by country and wealth quintile: crosssectional surveys in Southern Asia and sub-Saharan Africa. Bull World Health Organ 91, 914-922.

2. Gibbons L, Belizan JM, Lauer JA et al. (2012) Inequities in the use of cesarean section deliveries in the world. $A m J$ Obstet Gynecol 206, 331.e1-e19.

3. World Health Organization (2015) WHO Statement on Caesarean Section Rates. Geneva: WHO, Human Reproduction Programme.

4. Prior E, Santhakumaran S, Gale C et al. (2012) Breastfeeding after cesarean delivery: a systematic review and metaanalysis of world literature. Am J Clin Nutr 95, 1113-1135.

5. Perez-Escamilla R, Maulen-Radovan I \& Dewey KG (1996) The association between cesarean delivery and breastfeeding outcomes among Mexican women. Am J Public Health 86, 832-836.

6. Kuyper E, Vitta B \& Dewey K (2014) Implications of cesarean delivery for breastfeeding outcomes and strategies to support breastfeeding. Alive\&Thrive Technical Brief issue $8,1-9$.

7. Nissen E, Uvnäs-Moberg K, Svensson K et al. (1996) Different patterns of oxytocin, prolactin but not cortisol release during breastfeeding in women delivered by caesarean section or by the vaginal route. Early Hum Dev 45, 103-118.

8. Boccolini CS, Perez-Escamilla R, Giugliani ER et al. (2015) Inequities in milk-based prelacteal feedings in Latin America and the Caribbean: the role of cesarean section delivery. J Hum Lact 31, 89-98.

9. World Health Organization (1998) Evidence for the Ten Steps to Successful Breastfeeding. Geneva: WHO.

10. Patel A, Banerjee A \& Kaletwad A (2013) Factors associated with prelacteal feeding and timely initiation of breastfeeding in hospital-delivered infants in India. J Hum Lact 29, 572-578.

11. Banapurmath CR, Ramachandrappa S, Guruprasad G et al. (2013) Is cesarean section a barrier to early initiation of breastfeeding? Indian Pediatr 50, 1062-1063.

12. Brown CR, Dodds L, Attenborough R et al. (2013) Rates and determinants of exclusive breastfeeding in first 6 months among women in Nova Scotia: a population-based cohort study. CMAJ Open 1, E9-E17.

13. DiGirolamo AM, Grummer-Strawn LM \& Fein S (2008) Effect of maternity-care practices on breastfeeding. Pediatrics 122, Suppl. 2, S43-S49. 
14. Ekstrom A, Widstrom AM \& Nissen E (2003) Duration of breastfeeding in Swedish primiparous and multiparous women. J Hum Lact 19, 172-178.

15. Oficina Nacional de Estadística \& UNICEF (2015) Encuesta Nacional de Hogares de Propósitos Múltiples - Encuesta de Indicadores Múltiples por Conglomerados 2014, Resultados Principales. Santo Domingo, República Dominicana: Oficina Nacional de Estadística.

16. Centro de Estudios Sociales y Demográficos \& ICF International (2014) Encuesta Demográfica y de Salud 2013. Santo Domingo, República Dominicana: CESDEM and ICF International.

17. Corsi DJ, Neuman M, Finlay JE et al. (2012) Demographic and Health Surveys: a profile. Int J Epidemiol 41, 1602-1613.

18. Measure DHS (2015) The DHS Program. What We Do. Survey types. DHS methodology. http://www.dhsprogram. com/What-We-Do/Survey-Types/DHS-Methodology.cfm (accessed April 2015).

19. Rustein SO \& Johnson K (2004) The DHS Wealth Index. DHS Comparative Reports no. 6. Calverton, MD: ORC Macro.

20. Rustein SO \& Rojas G (2006) Guide to DHS Statistics: Demographic and Health Survey Methodology. Calverton, MD: Demographic and Health Surveys, ORC Marco.

21. Zanardo V, Pigozzo A, Wainer G et al. (2013) Early lactation failure and formula adoption after elective caesarean delivery: cohort study. Arch Dis Child Fetal Neonatal Ed 98, F37-F41.

22. Tuncalp O, Stanton C, Castro A et al. (2013) Measuring coverage in $\mathrm{MNCH}$ : validating women's self-report of emergency cesarean sections in Ghana and the Dominican Republic. PLoS One 8, e60761.

23. Villar J, Carroli G, Zavaleta N et al. (2007) Maternal and neonatal individual risks and benefits associated with caesarean delivery: multicentre prospective study. BMJ 335, 1025.

24. Silver RM, Landon MB, Rouse DJ et al. (2006) Maternal morbidity associated with multiple repeat cesarean deliveries. Obstet Gynecol 107, 1226-1232.

25. Black RE, Victora CG, Walker SP et al. (2013) Maternal and child undernutrition and overweight in low-income and middle-income countries. Lancet 382, 427-451.
26. Perez-Escamilla R, Segura-Millan S, Canahuati J et al. (1996) Prelacteal feeds are negatively associated with breastfeeding outcomes in Honduras. J Nutr 126, 2765-2773.

27. Haider R, Ashworth A, Kabir I et al. (2000) Effect of community-based peer counsellors on exclusive breastfeeding practices in Dhaka, Bangladesh: a randomised controlled trial. Lancet 356, 1643-1647.

28. Althabe F, Belizan JM, Villar J et al. (2004) Mandatory second opinion to reduce rates of unnecessary caesarean sections in Latin America: a cluster randomised controlled trial. Lancet 363, 1934-1940.

29. Donath SM \& Amir LH, ALSPAC Study Team (2003) Relationship between prenatal infant feeding intention and initiation and duration of breastfeeding: a cohort study. Acta Paediatr 92, 352-356.

30. Chu SY, Kim SY, Schmid CH et al. (2007) Maternal obesity and risk of cesarean delivery: a meta-analysis. Obes Rev $\mathbf{8}$, 385-394.

31. Amir LH \& Donath S (2007) A systematic review of maternal obesity and breastfeeding intention, initiation and duration. BMC Pregnancy Childbirth 7, 9.

32. Partridge S, Balayla J, Holcroft CA et al. (2012) Inadequate prenatal care utilization and risks of infant mortality and poor birth outcome: a retrospective analysis of $28,729,765$ US deliveries over 8 years. Am J Perinatol 29, 787-793.

33. Miller S, Cordero M, Coleman AL et al. (2003) Quality of care in institutionalized deliveries: the paradox of the Dominican Republic. Int J Gynaecol Obstet 82, 89-103.

34. Moore ER \& Anderson GC (2007) Randomized controlled trial of very early mother-infant skin-to-skin contact and breastfeeding status. I Midwifery Womens Health $\mathbf{5 2}$, $116-125$.

35. Bramson L, Lee JW, Moore E et al. (2010) Effect of early skin-to-skin mother-infant contact during the first 3 hours following birth on exclusive breastfeeding during the maternity hospital stay. J Hum Lact 26, 130-137.

36. Rowe-Murray HJ \& Fisher JR (2002) Baby friendly hospital practices: cesarean section is a persistent barrier to early initiation of breastfeeding. Birth 29, 124-131.

37. Declercq E (2015) Childbirth in Brazil: challenging an interventionist paradigm. Birth 42, 1-4. 